\title{
STUDENT'S PERFORMANCE AND ACADEMIC STRESS: A STUDY OF HIGHER EDUCATION INSTITUTION OF PAKISTAN
}

\author{
Faheem Akhter \\ Sobia Iqbal ${ }^{* *}$
}

\begin{abstract}
Based on empirical evidence and recent literature review, Stress has become an integral part of students' academic life due to the various internal and external expectations placed upon their shoulders. It therefore, becomes imperative to understand the sources and impact of academic stress in order to derive adequate and efficient intervention strategies. The five dimensions of sources such as Anxiety/stress, Student's Academic stress, Financial Constraints, Cultural dynamics, Students Performance were analyzed. This research finding is based on the responses obtained from 215 undergraduate students enrolled at a higher learning institution in Pakistan. This paper investigated the stressors, symptoms and effects that are likely to be experienced by the undergraduate students in higher Studies. The data was collected through self-administered questionnaires that were randomly floated on social media during the time of COVID19. Data obtained was analyzed using SPSS.
\end{abstract}

Keywords: Student performance; student's academic stress; anxiety/depression; financial constraints; cultural dynamics

\section{Introduction}

Academic performance is the most vital and concerning factor among the university students which is represented as GPA. Student's Academic Stress is a common aspect experienced by students. Scoring and maintaining the GPA somehow ensures a better future to the students and eventually a reason for the Students' Academic Stress (SAS) ${ }^{1}$.

Stress occurs when a person is unable to fulfill the demands of the required task due to forced exertion or mental retardants which results in failed task accomplishment as a student and abandoned academic performance ${ }^{2}$. Academic Stress is seen generally as student activities. University can impose challenges like workload, peer pressure, limited opportunities which is the cause of stress that is the root of anxiety and depression among students $^{3}$. Students might be stressed due to multiple factors like work-overload, social

\footnotetext{
${ }^{*}$ Faheem Akhter, Ph.D., Assistant Professor, HOD Management Sciences and Humanities, DHA Suffa University

** Sobia Iqbal, Ph.D., Assistant Professor, DHA Suffa University

${ }^{1}$ Halder, Ujjwal Kumar. 2018. "Academic Stress and Academic Performance among Higher Secondary Students, 6(1)."

${ }^{2}$ Richlin-Klonsky, J. \& Hoe, R. 2003. "Sources and Levels of Stress among UCLA Students.” Student Affairs Breifing,[2]

${ }^{3}$ Agolla, Joseph E., and Henry Ongroi. 2009. "An Assessment of Academic Stress Among." Department of Management, Faculty of Business, 4(2) 63-70
} 
status, fellow / companion students, financial constraints, anxiety/ depression, cultural dynamics etc.

Campbell (2006) defines stress as an opposite response: students have extreme pressure or other demands based on them. It occurs when a person meets a position that they feel amazing or cannot struggle with it. Among the university student strong connection is established among stressful events and poor academic achievements ${ }^{4}$.

\section{Background}

Erkutlu \& Chafra (2006), tension to achieve good grades in tests and allotment of time makes the situation more stressful for students. Stress reflects as a part of a student's academic life as an art to manage it and cope with the constraints of academic life. The course in academic life is constantly achieved with stress ${ }^{5}$.

Students have high hopes with their affiliated universities and treat it as a platform that opens up rooms for career opportunities. They can only be satisfied by such an environment that delivers them the peace where they can perform, progress, enhance and respond to the provided opportunities with prospects rather than get burdened by the management in stressful ways of learning and getting things done ${ }^{6}$. It has been assumed in many previous studies that the factors of academic performance are greatly affected by the stressful levels imposed on the students by the university ${ }^{7}$.

Literature analyzed key factors that were causing the academic stress and resulted in elaborating the cause for that. Some studies concluded that depression and anxiety resulted in negative effects on the students at Sri Aurobindo Medical College and P.G Institute, India.

\section{Research Questions}

a. What is the impact of academic stresses on a student's performance?

b. What is the impact of anxiety/depression on student's performance?

c. What is the impact of academic stress on student performance considering the cultural dynamics?

\footnotetext{
${ }^{4}$ Dusselier, Lauri, Yongyi Wang, Brian Dunn, and Mack C Shelley. 2005. "Personal, Health, Academic, and Environmental Predictors of Stress for Residence Hall Students." Journal of American College Health 54(1) $15-24$

${ }^{5}$ Erkutlu, Hakan, and Jamel Ben Chafra. 2006. "Relationship between Leadership Power Bases and Job Stress of Subordinates." Management Research News 29(5) 285-297

${ }^{6}$ Dhakal, Sandesh. 2001. "An Assessment of Academic Stress among." Journal of Central Department of Psychology 2(2)

${ }^{7}$ Kumar, S. \& Jejurkar, K. 2005. "Study of Stress Level in Occupational Therapy Students during their Academic Curriculum." The Indian Journal of Occupational Therapy, 37(1) 5-14
} 


\section{Research Objectives}

1. To explore the impression of academic stress on university enrolled students, and identify how it leads to low performance and distracts their goals.

2. To interpret the relationship between anxiety/depression, financial constraints on academic performance.

3. To categorize the impact of cultural dynamics in academic performance.

\section{Scope and Significance of the Study}

This study is steering the university enrolled students in Pakistan particularly in Karachi, exploring how Students Academic Stress affects their personal life, performance, finances, cultural dynamics, and lead to anxiety / depression.

The cultural dynamics have been ignored in literature. This study aims to highlight the cultural dynamics and explore how it can trouble a student's academic performance, further it will aid the student's understanding and lead to the academic institutions to view the picture from a different angle. It has been intended to fetch rational results to support and graft with the cultural dynamics understanding the causes and progress.

\section{Literature Review}

Stress has been discussed in literature in diverse perspectives but somehow limited research has been made from student's academic problems and performance dynamics. The existing studies support that there is an unhealthy relationship between stress and student's academic performance that not only affects the mental ability to work and results in low progress.

Progressive and analytical academic expectations are the need of today's competitive job market. To meet these expectations as a byproduct of highly ranked universities, the academic planning at times levies a lot on the students. The set deadlines act as a time bomb rather than enhancing the learning. This study will unwrap how top ranked universities' cultural dynamics affect the student's academic performance and acts as a stress factor.

Literature and past studies aimed to discuss the stressful factors that could be lowered to make the academic performance of the students better and progressive ${ }^{8}$.

A study was conducted to examine the rate of depression among the medical students of Fatima Jinnah Medical and Dental College. The data sample of 121 students was collected through questionnaires and SPSS was used to analyze the data which resulted that stress was due to the anxiety and depression created by faculty by giving too much of assignments and work to which they were not able to cope up with their academic and

${ }^{8}$ Sharma, Balkishan, and Rajshekhar Wavare. 2013. "Academic Stress due to Depression among Medical and Para-Medical Students in an Indian Medical College: Health Initiatives Cross Sectional Study." Journal of Health Sciences, 3(5) 29-38 
social life so they found it difficult to manage between their social and academic life and ended up being in the stressful working conditions ${ }^{9}$.

A study from Turkish University group of students examined the prevalence of depression, anxiety and stress among them. Dass-42 was used to examine 1617 respondents which resulted in the findings that, there is high prevalence of anxiety, depression and stress among the university students that was causing the effect on their academic performance too rather than the students who weren't depressed and were satisfied with their academic performance ${ }^{10}$.

\section{Stress, Anxiety / Depression}

A study by (Julian, 2006) treated students as independent variables and the stress as the dependent variable for his qualitative research framework. He analyzed the stress causing issues critically and categorized them as examination stress, financial pressure, peer pressure, transition to university and study generated stressors. In conclusion he discussed how student should respond to such stress and how stress management can help to reduce their negative impression mentally and behaviorally. He further stated that only a general qualitative perspective of the research is not enough to identify the true conclusion of stress and it can be measured in instrumental terms which can lead to better and experimental results ${ }^{11}$.

Cheryl, Glancy, \& Pitts (2013) qualitative research was a systematic study that conducted meta-analysis for the interventions to reduce the stress of the university students. They treated interventions of anxiety and depression reduction as independent variables whereas university students as dependent variables. The meta-analysis included 1431 students. The findings of the study showed that interventions such as behavioral, cognitive and mindfulness were effective to decrease the level of depression and anxiety among the university students so universities should take actions to introduce and launch such programs that helps the troubled students, stress them less so that they can perform well and get acknowledgement for their efforts ${ }^{12}$.

Siraj, Salam, R.Roslan, \& Hassan (2014), aimed their study to examine the negative impact of student's stress on academic performance and who it forbids them from achieving their goals. Stress is an ongoing process with mental health issues which refrain a person from doing their basic work. The study was carried out at Universiti Kebangsaan Malaysia with 179 responses. The data was analyzed through SPSS. They concluded that medical students of Universiti Kebangsaan Malaysia were successful in coping up with

\footnotetext{
${ }^{9}$ Maria, Altaf, Kisa F. Altaf, Salman Zahid, RabiaSharf, Ahsan Inayat, Muhammad Owais, and Hisham Usmani. 2013. "Medical students bearing mental stress due to their academic schedule." International Journal of Endorsing Health Science Research, 1(2) 93-97

${ }^{10}$ Bayram, Nuran, and Nazan Bilgel. 2008. "The prevelance and socio demoghraphic correlation of depression,anxiety and stress among a group of University students." Social pschiatry and Psychiatric Epidemiology, 43 667-672

${ }^{11}$ Julian, David Robotham:Claire. 2006. "Stress and the higher education student: a critical revview of the literature." Journal Of Further And Higher Education, 30(2) 107-117

${ }^{12}$ Cheryl, Regehr, Dylan Glancy, and Annabel Pitts. 2013. "Interventions to Reduce Stress in University Students:A review and meta-analysis.” Journal Of Affective Disorders,Vol.148 [1] 1-11
} 
their work and had a positive effect of the stress on their academic performance which meant they are well at managing their work and help the pressure to bring out the best possible outcomes ${ }^{13}$.

Al-Qaisy (2011), aimed to identify the relationship of anxiety and depression in academic achievement among university students with behavioral disorders to function and effect the academic performance of the students. The study was carried out in Tafila Technical University. It focused and concluded the varying demographic factors in the results. A random sample of 200 students from different faculties in university were taken with Pearson correlation tests. Depression and anxiety were taken as independent variables and academic performance as a dependent variable. The outcomes of the study showed that the depression is higher among university students and highlighted a negative relationship between depression and academic achievement whereas positive relationship between anxiety and academic achievement. It further explored that male participants are more in depression as compared to female participants while female participants experience more anxiety than male participants ${ }^{14}$.

Shamsuddin, et al., (2013), study identified the correlation among university students with depression, anxiety and stress. Students cop up with the stress and universities make them more stressful which results in common depression and anxiety which affects their mental health in young age. Depression, anxiety and stress has been treated as independent variables and university student's ad as dependent variables. The study took place at Klang Valley, Malaysia through different public universities, and the study collected 506 responses from the students aged 18-24. The collection has been analyzed by t-test and ANOVA tests. The study concluded as the symptoms of depression and anxiety is higher in the adult students age bracket (20 and above), and the stress was also higher in adult students so it means depression and stress were significantly higher in the students ${ }^{15}$.

As per Ibrahim, Kelly, Adams, \& Glazebrook (2013) study, the mental health issues are growing due to depression and are marked as the third most found disease after heart and respiratory health issues ${ }^{16}$.

Their work highlighted the reasons for higher depression frequency in university enrolled students is academic stress and other related factors impacting their studies. This article was carried out to identify depression as a problem in the university students for which different articles from 1990 -2009 were studied from PubMed, BioMed Centre and Medline to state a qualitative research about the theory of depression among university

\footnotetext{
${ }^{13}$ Siraj, Harlina Haliza, Abdus Salam, R.Roslan, and N.A Hassan. 2014. "Stress and its association with the Academic Performance of undergradute fourth year medical students at Universiti Kebangsaan Malaysia." Internation Medical Journal Malaysia,13 (1) 19-24

${ }^{14}$ Al-Qaisy, Lama M. May 2011. "The relation of depression and anxiety in academic achievement among group of university students.” International Jurnal Of Counselling And Pshycology, 3(5) 96-100

${ }^{15}$ Shamsuddin, Khadijah, Fariza Fazdil, Wan Salwina Wan Ismail, Shamsul Azhar Shah, Khairani Omar, Noor Azimah Muhammad, Aida Jaffar, Aniza Ismail, and Raynuha Mahadevan. August 2013. "Correlates of Depression, Anxiety and Stress among Malaysian University Students.” Asian Journal Of Psychiatry,Vol.6 [4] 308-323

${ }^{16}$ Ibrahim, Ahmed K., Shona J. Kelly, Clive E. Adams, and Cris Glazebrook. n.d. "A systematic review of studies of depression prevalence in university students.
} 
students. The study concluded that those who don't study at university are at low risk of depression whereas the people enrolled in university face depression symptoms and even depression itself at an early age.

\section{Financial Constraints}

A study of Callender \& Jackson (2005) debated for the impact of debt resulting in deterioration of students from higher education. The study highlights the financial constraints that become barriers for students to continue their studies or even result in dropout. In their study they considered Debt as an independent variable and higher education was a dependent variable. The results of this quantitative study conclude that social class / status is the only barrier for students and restricts them to enroll in the Higher Educational Institutions. Higher social class students do not feel financial burden whereas the students from lower class fear for debt and therefore are unable to pursue higher education. This situation might be a strong factor for stressful conditions or that they achieve their education properly. This study recommends and suggests to look into the policies and fix the class difference between the students so that every student can get its basic Higher Education to be need fulfilled ${ }^{17}$.

T.Curtis (2008), study aimed to identify 3 elements in his qualitative research study ${ }^{18}$,

a) How does financial instability cause dropouts in the higher education system?

b) How does financial problems cause low performance in the academics of the students?

c) How does academic advisors help students with financial problems?

The research highlighted financial constraints and treated them as independent variables considering the financial debt students have to pay as fee in their academic years, consequence students in stressful condition and academic advisors as dependent variable, assuming that the academic advisors can advise to the students facing financial problems and guide them to tackle them at the campus. This is how the academic institutions support and encourage them to continue their higher studies.

\section{Cultural Dynamics}

The aim of Manalo, Kusumi, Koyasu, Michita, \& Tanaka (2013) study was to identify how cultural dynamics influence university students. They treated Cultural dynamics as independent variables and university students as dependent variables for the data of 363 university undergraduate students from Japan, New Zealand and Auckland. They analyzed the data by critical thinking based on self-construal, self-efficiency and

\footnotetext{
${ }^{17}$ Callender, Claire, and Jonathan Jackson. 2005. "Does the fearr of Debt Deter Students from Higher Education." Journal Of Social Policy, 34(04) 509-540

${ }^{18}$ T.Curtis, Reed. 2008. "Students in Financial Crises:How Academic Advisors can help." The Mentor:An Academic Advicing Journal 1-7
} 
regulatory mode factors. The results find out that cultural and related dynamics affect the university students for critical thinking and are correlated ${ }^{19}$.

Bataineh (2013), study aim to study was to investigate the consequence of academic stressors on university students and how it stresses their performance. Stressors were independent variables and university students were dependent variables. Data was obtained by faculty of King Saud University by taking a sample of 232 participants. ANOVA, correlation and descriptive analysis was used to analyze the data collected data. The conclusion stated that cultural factors such as low motivation, course awkwardness, small and limited time to study, teacher inconvenience were responsible for bringing stress among the university students and the study explored that the main reason of stress among the university students was the fear of failure ${ }^{20}$.

\section{Academic Performance}

Hendres (2011) study interpret s the relationship between social identity and social perception as independent variable and academic performance which as dependent variable. Two sample sizes of $\mathrm{N}=97$ and $\mathrm{N}=110$ were taken to carry out the results. Study concludes the importance of social identity and social perception, it is mandatory for learning in the university in terms of academic performance. The findings of this study are that great social identity will lead to adequate performance and social perception act as a value to effective learning ${ }^{21}$.

The aim of Elias, Ping, \& Abdullah, (2011) study was to identify stress among university students from a local university and their academic achievement. Stress was considered as an independent variable and academic achievement as dependent variable. Cluster sampling was selected and the data of 376 undergraduate students has been collected. Results showed that both levels of stress are found in undergraduate students and the students studying in their first year of the university have lower levels of stress whereas medical students were found to have the most stressful levels in their academic years ${ }^{22}$.

The current study will identify the relationship of academics' stress with student performance from the cultural perspective of Pakistan. It will assist to improve student's performance and reduce academic stress.

\footnotetext{
${ }^{19}$ Manalo, Emmanuel, Takashi Kusumi, Masou Koyasu, Yashushi Michita, and Yoku Tanaka. December 2013. "To what extent do culture-related factors influence university students' critical thinking use?" Thinking Skills and Creativity,Vol.10 121-132

${ }^{20}$ Bataineh, Marwan Zaid. 2013. "Academic Stress among Undergraduate Student: The Case Of Education Faculty at King Saud University." International Interdisciplinary Journal Of Education, Vol.2 [1] 82-88

${ }^{21}$ Hendres, Ana-Maria Bliuc:Robert A. Ellis:Peter Goodyear:Daniela Muntele. 2011. "Understanding student learning in context: relationships between university students' social identity, approaches to learning, and academic performance." European Journal of Pshycology of Education, 26(3) 417-433

${ }^{22}$ Elias, Habibah, Wong Siew Ping, and Maria Chong Abdullah. 2011. "Stress and Academc Achievement Among Undrgraduate Students in Univeriti Putra Malaysia." Procedia-Social and behavioal Sciences,Vol.29 646-655
} 


\section{Framework}

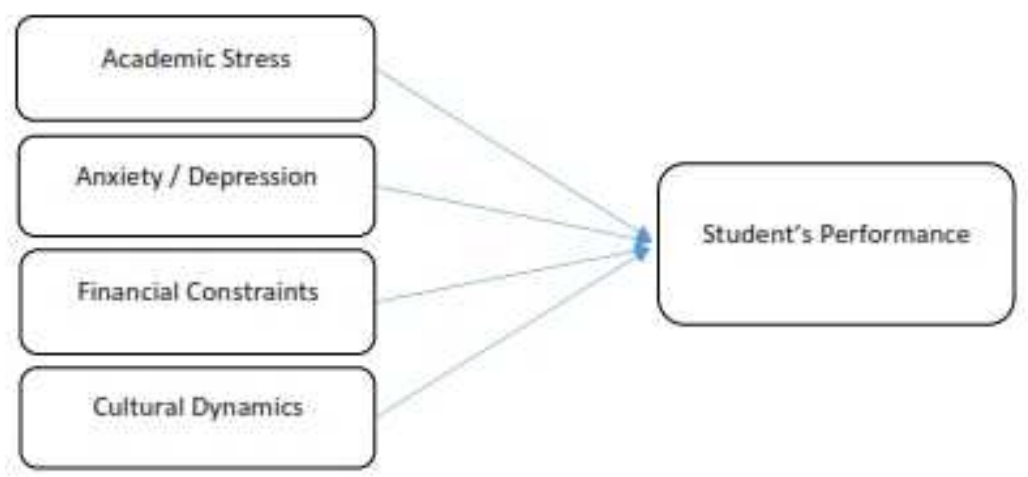

In the above framework Anxiety/depression (AD), Stress (ST), Financial Constraints (FC) and Cultural Dynamics (CD) are taken as independent variables whereas Student's Performance (SP) as dependent variable.

\section{Hypotheses}

$\mathrm{Ho}_{1}$ : There is no significant relationship between anxiety / depression and a student's academic performance.

$\mathrm{Ho}_{2}$ : There is no significant relationship between Academic stress and student's academic performance.

$\mathrm{Ho}_{3}$ : There is no significant relationship between Financial Constraints and student's academic performance.

Ho 4 : There is no significant relationship between Cultural Dynamics and student's academic performance.

\section{Research Methodology}

Research methodology explains the science that how the research is scientifically directed? It explains how the research problems are scientifically solved. The primary data for this particular exploratory natured study has been collected through questionnaires as per quantitative parameters and the literature review has been considered as secondary data. After narrowing down to the specific hypothesis deductive approach has been used.

The data of this cross-sectional study has been collected from 215 participants (students) enrolled in Higher Educational Institutes residing particularly in Karachi through convenience sampling method. The survey questionnaire is based on Likert scale and the data has been analyzed through SPSS software (Regression, Correlation, Cronbach Alpha, descriptive analysis) to identify the influence of dependent and independent variables. A self-explanatory questionnaire has been floated on social media in order to collect the 
responses from university enrolled students in Karachi. Multiple regression analysis has been conducted whenever more than one independent variable exists to investigate the impact on dependent variable ${ }^{23}$.

\section{Results and Findings}

The demographic profile of the respondents has been analyzed to explore the factors that have a significant impact on student's academic stress and their performance.

\section{Demographics Profile}

\begin{tabular}{|c|c|c|c|c|c|}
\hline \multicolumn{2}{|c|}{ Table 1 } \\
\hline \multicolumn{2}{|c|}{ Age } & Frequency & Percentage & Valid Percentage & Cumulative Percentage \\
\hline \multirow{5}{*}{ Valid } & $18-22$ & 125 & 58.1 & 58 & 58 \\
\cline { 2 - 6 } & $23-26$ & 71 & 33 & 33 & 91 \\
\cline { 2 - 6 } & $27-30$ & 19 & 8.8 & 9 & 100 \\
\cline { 2 - 6 } & Total & 215 & 100 & 100 & \\
\hline
\end{tabular}

Table No 1 is representing the data of 215 participants in terms of their age. It is reflecting that 125 participants are between 18-22 years old (57.7\%), 71 (33\%) are between 23-26 years old, and $19(8.8 \%)$ of them are in the range of 27-30 years old.

\begin{tabular}{|c|c|c|c|c|c|}
\hline \multicolumn{6}{|c|}{$\begin{array}{c}\text { Table } 2 \\
\text { Participant's Gender of the Untversity Enrolled Students }\end{array}$} \\
\hline \multicolumn{2}{|c|}{ Gender } & Frequency & Percentage & Valid Percentage & Cumulative Percentage \\
\hline \multirow{3}{*}{ Valid } & Male & 107 & 49.8 & 50 & 50 \\
\hline & Female & 108 & 50.2 & 50 & 100 \\
\hline & Total & 215 & 100 & 100 & \\
\hline
\end{tabular}

Table No 2 is representing the data of 215 participants in terms of their gender. It is reflecting that 107(50\%) are males and $108(50 \%)$ are females.

${ }^{23}$ Zikmund, William G., Barry J. Babin, John C. Carr, and Mitch Griffin. 2013. "Business Research Methods." Cengage Learning 


\begin{tabular}{|c|c|c|c|c|c|}
\hline \multicolumn{6}{|c|}{ Table 3 } \\
\hline \multicolumn{2}{|c|}{ Edurticipant's Qualification of the University Earolled Students } \\
\hline \multirow{3}{*}{ Valid } & Frequency & Percentage & $\begin{array}{c}\text { Valid } \\
\text { Percentage }\end{array}$ & $\begin{array}{r}\text { Cumulative } \\
\text { Percentage }\end{array}$ \\
\cline { 2 - 6 } & Post Graduate & 39 & 18.1 & 82 & 82 \\
\cline { 2 - 6 } & Total & 215 & 100 & 18 & 100 \\
\hline
\end{tabular}

Table No 3 is representing the data of 215 participants in terms of their educational qualification. It is reflecting that $176(82 \%)$ respondents are under-graduate, whereas 39 (18\%) respondents are post-graduate

\begin{tabular}{|c|c|c|c|c|c|}
\hline \multicolumn{6}{|c|}{$\begin{array}{c}\text { Table 4 } \\
\text { Income of the University Enrolled Students }\end{array}$} \\
\hline \multicolumn{2}{|c|}{$\begin{array}{c}\text { Income in Thousand } \\
\text { Rupees }\end{array}$} & Frequency & Percentage & $\begin{array}{c}\text { Valld } \\
\text { Percentage }\end{array}$ & $\begin{array}{l}\text { Cumulative } \\
\text { Percentage }\end{array}$ \\
\hline \multirow{5}{*}{ Valid } & $25-30$ & 50 & 23.3 & 23.3 & 22.3 \\
\hline & $31-60$ & 48 & 22.4 & 22.4 & 45.7 \\
\hline & $61-100$ & 39 & 18.1 & 18.1 & 63.8 \\
\hline & 101 and above & $\overline{78}$ & 36.2 & 36.2 & 100 \\
\hline & Total & 215 & 100 & 100 & \\
\hline
\end{tabular}

Table No 4 is representing the data of 215 participants in terms of income. It is reflecting that $78(36.2 \%)$ respondents income is more than $101 \mathrm{~K}$ per month whereas $50(23.3 \%)$ respondents income is $25-30 \mathrm{~K}$ per month.

\section{Results with Tabulation and Discussion}

\begin{tabular}{|c|c|}
\hline \multicolumn{2}{|c|}{$\begin{array}{c}\text { Table } 5 \\
\text { Reliability Statistics }\end{array}$} \\
\hline Cronbach's Alpha & N of Items \\
\hline 0.752 & 5 \\
\hline
\end{tabular}

Table No 5 is reflecting the analysis of Cronbach alpha Reliability positive results with a value of 0.752 as $75.2 \%$ of variance. Reliability shows the consistency of the questionnaire. 


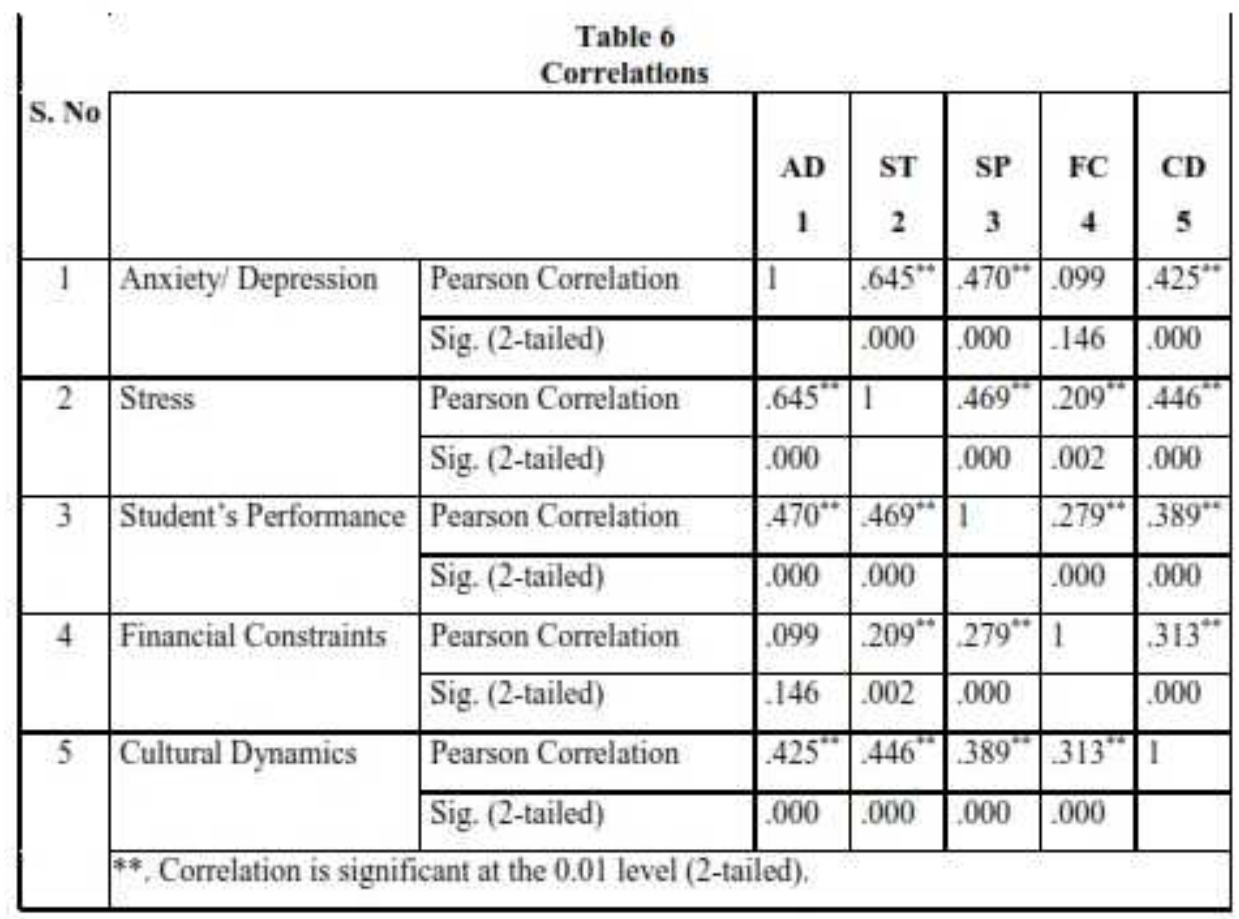

Table No 6 is representing the Correlation results of the data as under;

- The Correlation coefficient result of AD and ST is 0.645 , and the p value is 0.000 . It reflects that there is a strong and positive correlation among the two selected variables.

- The Correlation coefficient result of AD and SP is 0.470 and the p value is 0.000 . It reflects that there is strong and positive correlation among the two variables.

- The Correlation coefficient result of AD and FC is 0.99 and the p value is 0.146. It reflects that there is an insignificant relationship between the two variables.

- The Correlation coefficient result of AD and CD is 0.425 and the p value is 0.000 . It reflects that they have a strong and positive relationship in the 2 tested variables.

- The Correlation coefficient results of ST and SP is 0.469 and the p value is 0.000 showing positive and strong relationship between the two variables.

- The Correlation coefficient result of ST and FC is 0.209 and the $\mathrm{p}$ value is 0.002 . It reflects that the correlation among the two variables is strong and positive.

- The Correlation coefficient results of ST and CD is 0.446 and the p value is 0.000 . It reflects the correlation among the two variables is strong and positive. 
- The Correlation coefficient results of $\mathbf{S P}$ and $\mathbf{F C}$ is 0.279 and the p value is 0.000 . It reflects that the correlation among the two variables is strong and positive.

- The Correlation coefficient result of SP and CD is 0.389 and the p value is 0.000 . It reflects that the correlation among the two variables is significant.

- The Correlation coefficient results of $\mathbf{F C}$ and $\mathbf{C F}$ is 0.313 and the $\mathrm{p}$ value is 0.000 . It reflects that the correlation among the two variables is strong, significant and positive.

\begin{tabular}{|l|c|c|c|c|c|c|c|c|c|}
\hline \multicolumn{10}{|c|}{ Table 7 } \\
\hline & & & & & \multicolumn{5}{c|}{ Change Statistics } \\
\cline { 5 - 9 } Model & $\mathbf{R}$ & $\mathbf{R}^{2}$ & Adj. $\mathbf{R}^{2}$ & Std. Error & $\mathbf{R}^{2}$ Change & F Change & df1 & df2 & Sig. F Change \\
\hline 1 & $565^{5}$ & 319 & 306 & .61735 & 319 & 24.564 & 4 & 210 & .000 \\
\hline
\end{tabular}

The above table 7 is representing the value of $\mathrm{R}^{2}$ as 0.319 reflecting $31 \%$ variance on dependent variables.

\begin{tabular}{|c|c|c|c|c|c|c|}
\hline \multicolumn{7}{|c|}{$\begin{array}{c}\text { Table } 8 \\
\text { ANOVAa }\end{array}$} \\
\hline & Model & Sum of Squares & df & Mean Square & F & Slg. \\
\hline \multirow[t]{3}{*}{$T$} & Regression & 37.447 & $\overline{4}$ & $\overline{9.362}$ & 24.564 & $.000^{5}$ \\
\hline & Residual & 80.034 & 210 & 381 & & \\
\hline & Total & 117.481 & 214 & & & \\
\hline \multicolumn{7}{|c|}{ a. Dependent Variable: SP } \\
\hline & tors: (Con & , Cf, FC, AD, ST & & & & \\
\hline
\end{tabular}

The value of significance shows a value of 0.000 which shows significant relationship on the model because its overall value is less than 0.05 , therefore the model is considered to be fit. 


\begin{tabular}{|c|c|c|c|c|c|c|}
\hline \multicolumn{7}{|c|}{$\begin{array}{c}\text { Table } 9 \\
\text { Coeffictents }\end{array}$} \\
\hline & \multirow[b]{2}{*}{ Model } & \multicolumn{2}{|c|}{$\begin{array}{l}\text { Unstandardized } \\
\text { Coefficients }\end{array}$} & \multirow{2}{*}{\begin{tabular}{|r}
$\begin{array}{l}\text { Standardized } \\
\text { Coefficlents }\end{array}$ \\
Beta
\end{tabular}} & \multirow[b]{2}{*}{$t$} & \multirow[b]{2}{*}{ Sig. } \\
\hline & & B & Std. Error & & & \\
\hline \multirow[t]{5}{*}{1} & (Constant) & 1.482 & .263 & & 5.639 & .000 \\
\hline & $\begin{array}{l}\text { Anxiety / } \\
\text { Depression }\end{array}$ & .224 & .064 & .266 & 3.482 & .001 \\
\hline & Stress & .174 & .067 & .202 & 2.608 & .010 \\
\hline & $\begin{array}{c}\text { Financial } \\
\text { Constraints }\end{array}$ & .168 & .060 & .169 & 2.797 & .006 \\
\hline & Cultural Dynamics & .102 & .052 & .132 & 1.963 & .051 \\
\hline
\end{tabular}

Dependent $=$ B (Independent variable $)+$ constant

$\mathrm{SP}=1.482(0.224+0.174+0.168+0.102)+$ constant

The table of coefficients representing the relationship of the independent and dependent variable. The results showed all the positive B coefficients. The only significant beta coefficient with p-value 0.001 less than 0.05 is the Anxiety / Depression variable with B .224 , which indicates there is a strong and significant relationship between the Anxiety / Depression and Student's Performance.

The Stress has B.174, p-value $>0.05$, the value of p 0.10 is more than 0.05 which means it is insignificant. The Financial Constraints has B.168, p-value > 0.05, the value of $p$ 0.006 is more than 0.05 which means it is insignificant. The Cultural Dynamics has B.102, $\mathrm{p}$-value $>0.05$, the value of $\mathrm{p} 0.51$ is more than 0.05 which means it is insignificant.

\section{Interpretation of Hypotheses}

$\mathrm{H}_{1}$ : There is no significant relationship between anxiety / depression and a student's academic performance.

The tested significance value of anxiety/depression (AD) is.001 $(<0.05)$. Hence the alternate hypothesis is accepted after determining that student performance is associated with anxiety/depression.

$\mathrm{H} 2$ : There is no significant relationship between Academic stress and student's academic performance. 
The tested significance value of Stress (ST) is .010 (0.05>). Hence it is proved that our alternate hypothesis is rejected. Academic stress has no influence on student performance.

H3: There is no significant relationship between Financial Constraints and student's academic performance.

The tested Significance value of Financial Constraints $(F C)$ is .006 (0.05>). Hence it is proved that the alternate hypothesis is rejected, representing that Financial Constraints has no influence on Student's Performance.

H4: There is no significant relationship between Cultural Dynamics and student's academic performance.

The tested Significance value of Cultural Dynamics (CD) is .051 (0.05>). Hence it is proved that the alternate hypothesis is rejected, representing that Cultural Dynamics has no influence on Student's Performance.

The results of this exploratory research investigated that Anxiety / Depression proved as significant impression on Student's Performance whereas the other selected factors (Academic Stress, Financial Constraints, and Cultural Dynamics) had no significant impact on the Student's Performance.

\section{Discussion, Recommendations and Conclusion}

This study attempted to find the impact of Student's Academic Stress on Students Performance towards Anxiety / Depression, Academic Stress, Financial Constraints, and Cultural Dynamics. The results of this exploratory research investigated that Anxiety / Depression proved as significant impression on Student's Performance whereas the other selected factors (Academic Stress, Financial Constraints, and Cultural Dynamics) had no significant impact on the Student's Performance.

The previous study shows that few students participated in a study conducted to explore the coping strategies to reduce their anxiety, and concluded that those students who are engaged in the breathing exercise and social supporting activities are productively progressive in their academic activities. (Samson-Akpan et al., 2017).

According to the analysis and findings of this study it is concluded that anxiety/depression impacted the student performance. Based on the findings above, following are the few recommendations:

- The faculty members should provide substantial study material to the students and guide them properly for the examination.

- Seminars, workshops and consulting hours should be set up to avoid the load of the courses. 
- Considering the importance of the Student's Counselor, cognitive therapy and interpersonal therapy should be adopted if the student is suffering from anxiety/depression.

- Higher Educational Institutes should arrange social events to enhance the confidence of the students, guiding them for future moves, self-assurance to reduce anxiety and improve student progress.

- Although the mental health of students should be the main area of concern for the academic institutions, sadly it remains untapped and there is no active action to it.

\section{Bibliography}

Agolla, Joseph E., and Henry Ongroi. 2009. "An assessment of academic stress among." Department Of Management, Faculty of Business4(2) 63-70.

Al-Qaisy, Lama M. May 2011. "The relation of depression and anxiety in academic achievement among group of university students." International Jurnal Of Counselling And Pshycology, 3(5) 96-100.

Bataineh, Marwan Zaid. 2013. "Academic Stress among Undergraduate Student: The Case Of Education Faculty at King Saud University." International Interdisciplinary Journal Of Education, Vol.2 [1] 82-88.

Bayram, Nuran, and Nazan Bilgel. 2008. "The prevelance and socio demoghraphic correlation of depression,anxiety and stress among a group of University students." Social pschiatry and Psychiatric Epidemiology, 43 667-672.

Callender, Claire, and Jonathan Jackson. 2005. "Does the fearr of Debt Deter Students from Higher Education." Journal Of Social Policy, 34(04) 509-540.

Cheryl, Regehr, Dylan Glancy, and Annabel Pitts. 2013. "Interventions to Reduce Stress in University Students:A review and meta-analysis." Journal Of Affective Disorders, Vol.148 [1] 1-11.

Dhakal, Sandesh. 2001. "An Assessment of Academic Stress among." Journal of Central Department of Psychology2(2).

Dusselier, Lauri, Yongyi Wang, Brian Dunn, and Mack C Shelley. 2005. "Personal, health, academic, and environmental predictors of stress for residence hall students." Journal of American College Health 54(1) 15-24.

Elias, Habibah, Wong Siew Ping, and Maria Chong Abdullah. 2011. "Stress and Academc Achievement Among Undrgraduate Students in Univeriti Putra Malaysia." Procedia-Social and behavioal Sciences, Vol.29 646-655. 
Erkutlu, Hakan, and Jamel Ben Chafra. 2006. "Relationship between leadership power bases and job stress of subordinates." Management Research News 29(5) 285-297.

Erkutlu, Hakan, and Jamel Ben Chafra. 2001. "Relationship between leadership power bases and job stress of subordinates." Management Research News 29(5) 285-297.

Halder, Ujjwal Kumar. 2018. "Academic stress and academic performance among higher secondary students6(1)."

Hendres, Ana-Maria Bliuc:Robert A. Ellis:Peter Goodyear:Daniela Muntele. 2011. "Understanding student learning in context: relationships between university students' social identity, approaches to learning, and academic performance." European Journal of Pshycology of Education, 26(3) 417-433.

Ibrahim, Ahmed K., Shona J. Kelly, Clive E. Adams, and Cris Glazebrook. 2013. "A systematic review of studies of depression prevalence in university students." Journal of Psychiatric Research 47 (3): 391-400.

Julian, David Robotham:Claire. 2006. "Stress and the higher education student: a critical revview of the literature." Journal Of Further And Higher Education, 30(2) 107-117.

Kumar, S. \& Jejurkar, K. 2005. "Study of Stress Level in Occupational Therapy Students during their Academic Curriculum." The Indian Journal Of Occupational Therapy,37(1) 5-14.

Manalo, Emmanuel, Takashi Kusumi, Masou Koyasu, Yashushi Michita, and Yoku Tanaka. December 2013. "To what extent do culture-related factors influence university students' critical thinking use?" Thinking Skills and Creativity, Vol.10 121-132.

Maria, Altaf, Kisa F. Altaf, Salman Zahid, RabiaSharf, Ahsan Inayat, Muhammad Owais, and Hisham Usmani. 2013. "Medical students bearing mental stress due to their academic schedule." International Journal of Endorsing Health Science Research, 1(2) 93-97.

Richlin-Klonsky, J. \& Hoe, R. 2003. "Souces and Levels of Stress among UCLA Students." Student Affairs Breifing, [2].

Shami, Usman, Nouman Ali, and Zohaib Ur Rehman. 2015. "Determinant's of Job Satisfaction and Employee Turnover in Pakistan Paint Industry." European Journal of Business and Management.

Shamsuddin, Khadijah, Fariza Fazdil, Wan Salwina Wan Ismail, Shamsul Azhar Shah, Khairani Omar, Noor Azimah Muhammad, Aida Jaffar, Aniza Ismail, and Raynuha Mahadevan. August 2013. "Correlates of Depression, Anxiety and Stress among Malaysian University Students." Asian Journal Of Psychiatry, Vol.6 [4] 308-323. 
Sharma, Balkishan, and Rajshekhar Wavare. 2013. "Acdemic stress due to depression among medical and para-medical students in an Indian Medical College: Health initiatives cross sectional study." Journal of Health Sciences, 3(5) 29-38.

Siraj, Harlina Haliza, Abdus Salam, R.Roslan, and N.A Hassan. 2014. "Stress and its association with the Academic Performance of undergradute fourth year medical students at Universiti Kebangsaan Malaysia." Internation Medical Journal Malaysia,13 (1) $19-24$.

T.Curtis, Reed. 2008. "Students in Financial Crises:How Academic Advisors can help." The Mentor:An Academic Advicing Journal 1-7.

Zikmund, William G., Barry J. Babin, John C. Carr, and Mitch Griffin. 2013. "Business Research Methods." Cengage Learning. 